\title{
Impact factors, citation distributions and journal stratification
}

\author{
Christopher F. Blanford ${ }^{1, *}$ \\ ${ }^{1}$ School of Materials and Manchester Institute of Biotechnology, University of Manchester, 131 Princess Street, Manchester M1 7DN, \\ UK
}

Published online:
12 August 2016
C) Springer Science+Business
Media New York 2016

This past July, an international team of researchers and publishers published a proposal that academic journals share their citation distributions to encourage authors, publishers and institutions to look beyond using single numerical metrics for an entire journal as a proxy for the research quality of individual articles in it [1]. We embrace this effort and include the citation distribution that contributed to this Journal's 2015 Thomson Reuters Impact Factor.

A journal impact factor (JIF) is a simple ratio. The numerator is the number of citations a journal receives in a particular calendar year to 'citable items' with a publication date from the previous two years (the 'citation window'). The denominator is the number of citable items in that citation window. Citable items include reviews and original research, which Thomson Reuters classify as 'articles'. Editorials, such as this one, are classified as 'editorial material' and are not counted in the denominator.
Although the classification protocol has been defined [2], there is still a lot of grey area [3], ${ }^{1}$ particularly in publications that fall somewhere between scientific journals and society membership magazines. ${ }^{2}$

In 2013 and 2014, the Journal of Materials Science published 1818 items, comprising 1768 articles ( $97.2 \%$ of content), 44 reviews $(2.4 \%), 5$ editorials and 1 correction. The citation distribution pattern for articles and citations that contributed to our $2015 \mathrm{JIF}$ is shown in Fig. 1. Citations to reviews and other items, shown in orange in the plot, contributed to about $10 \%$ of our 2015 JIF.

\footnotetext{
${ }^{1}$ For example, none of the articles published in 2013 and 2014 in Acta Materialia are classified as reviews, including their topcited article from the period which includes the phrase 'which we summarise in this concise review' in the abstract.

2 The archetype in the 'Materials Science, Multidisciplinary' category is the MRS Bulletin. The distinction between journal and magazine is especially blurred in titles such as Science and Nature where news, book reviews, and commentaries comprise about half the items and more than a quarter of the published pages.
}

Address correspondence to E-mail: christopher.blanford@manchester.ac.uk 


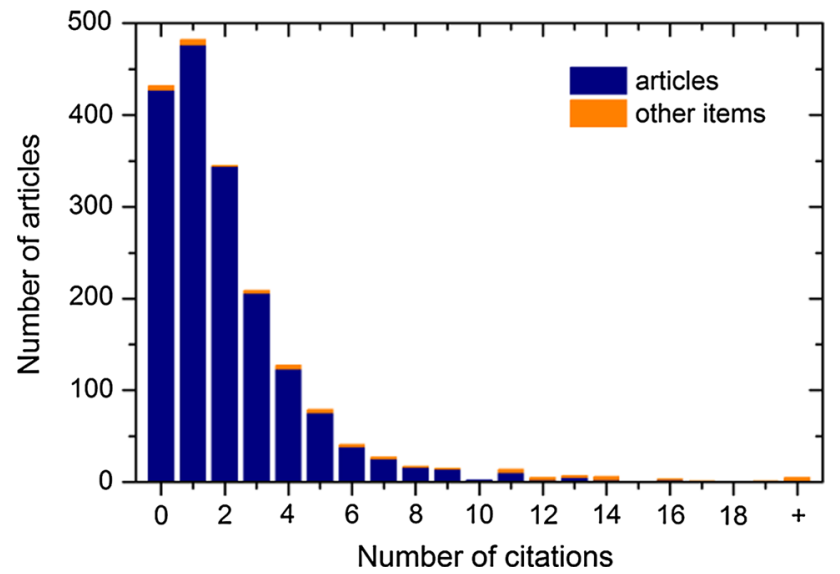

Figure 1 Distribution of citations from articles published in 2015 to articles published in the Journal of Materials Science in 2013 and 2014 (volumes 49 and 50). The orange segments at the top of each column represent the contribution from document types such as reviews or editorial content.

The long tail clearly highlights the problem of using an arithmetic mean to describe such as skewed distribution. ${ }^{3}$ About $70 \%$ of articles published in 2013 and 2014 in the Journal of Materials Science were cited fewer times than the value of the 2015 JIF. Table 1 shows that this is consistent with three other materials science journals, regardless of JIF. This is also consistent with the observation from Larivière and co-workers in their survey of 11 other journals where $65-75 \%$ of citable items had fewer citations than the JIF [1].

Also in line with the findings from Larivière, we see that the cumulative citation distribution function for all these selected journals is nearly identical (Fig. 2). Each follows a pattern close to a Pareto distribution, like those used to model income distributions. This power-law probability distribution is most familiar in the specific case known as the 'Pareto principle' or ' $80-20$ rule'. For example, $80 \%$ of the world's income goes to $20 \%$ of the population, if the rule holds. ${ }^{4}$ For article citations, we see something

\footnotetext{
${ }^{3}$ An extreme example of this are the 2009 and 2010 JIFs for Acta Crystallographica A, which was boosted from around 2 to around 50 for those years on the basis of a single review of a programme used to refine the X-ray structure of small molecules. The article, which has nearly 50,000 citations to date, pushed the journal to the second spot on the JIF league table for those two years, just behind CA: A Cancer Journal of Clinicians.

${ }^{4}$ In the USA, it works out that $65 \%$ of income goes to $35 \%$ of people, based on the 2013 Gini index from the World Bank. http:/ / data.worldbank.org/indicator/SI.POV.GINI accessed 2016-08-03.
}

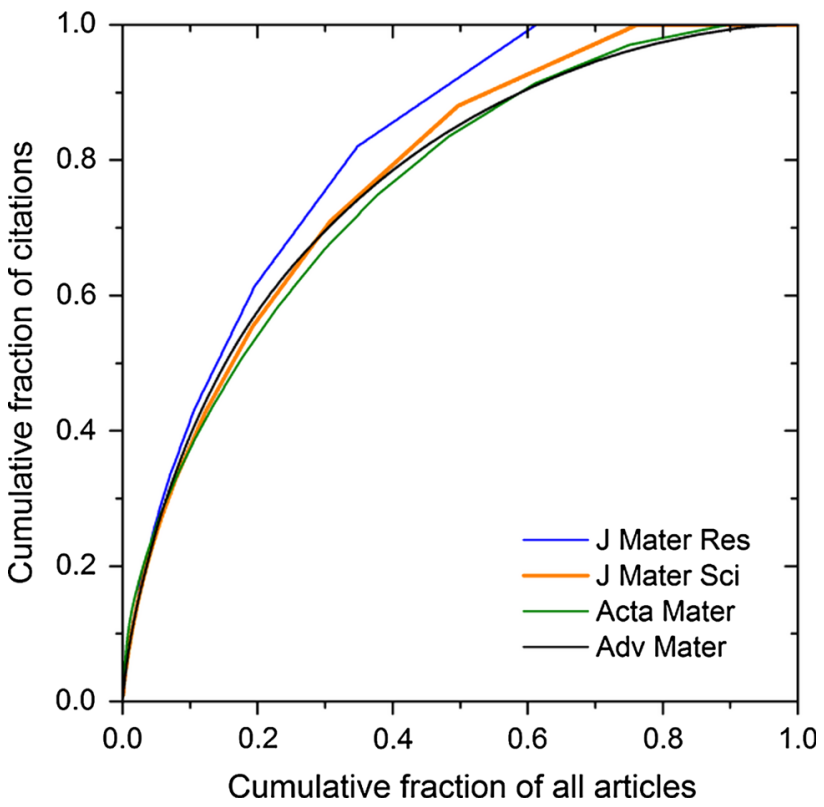

Figure 2 The cumulative percentage of articles published in four materials science journals in 2013 and 2014, and the citations to them in 2015. Modelled after Larivière et al. [1].

closer to a '70-30 rule': $70 \%$ of a journal's citations come from about $30 \%$ of the published articles.

If all journals have a similar citation distribution regardless of the size of their JIF, then what is the problem with using this metric? The danger is the prejudice that this oversimplification engenders. By assuming the quality of an unread article based on the journal in which it appeared, we risk ignoring relevant work and not being up-to-date with one's field. When a JMS Editor asked one contributor why he had not cited a relevant paper, his reply was 'it was not in a high-impact journal'!

There is an additional corrosive effect on academic publishing, illustrated in Fig. 3: the 'rich' get richer and the 'poor' get poorer. Histograms of JIFs for materials science journals for any given year consistently fit a lognormal distribution (top panel). If you trace back the JIFs from the journals in each category, as illustrated in the bottom panel, you see two clear trends.

First, there is a steady increase in impact factors. The median impact factor has gone up by 0.6 (66 \%) to 1.6 over the decade, while the mean (average) impact factor has increased by $1.2(76 \%)$ to 2.9 in the same period. ${ }^{5}$

\footnotetext{
5 The number of titles in the category 'Materials Science, Multidisciplinary' grew markedly over the survey period, from 175 in 2006 to 270 in 2015. For the bottom panel of Fig. 3, the plots of mean impact factor with time cover fewer journals for the older values than for the newer ones.
} 


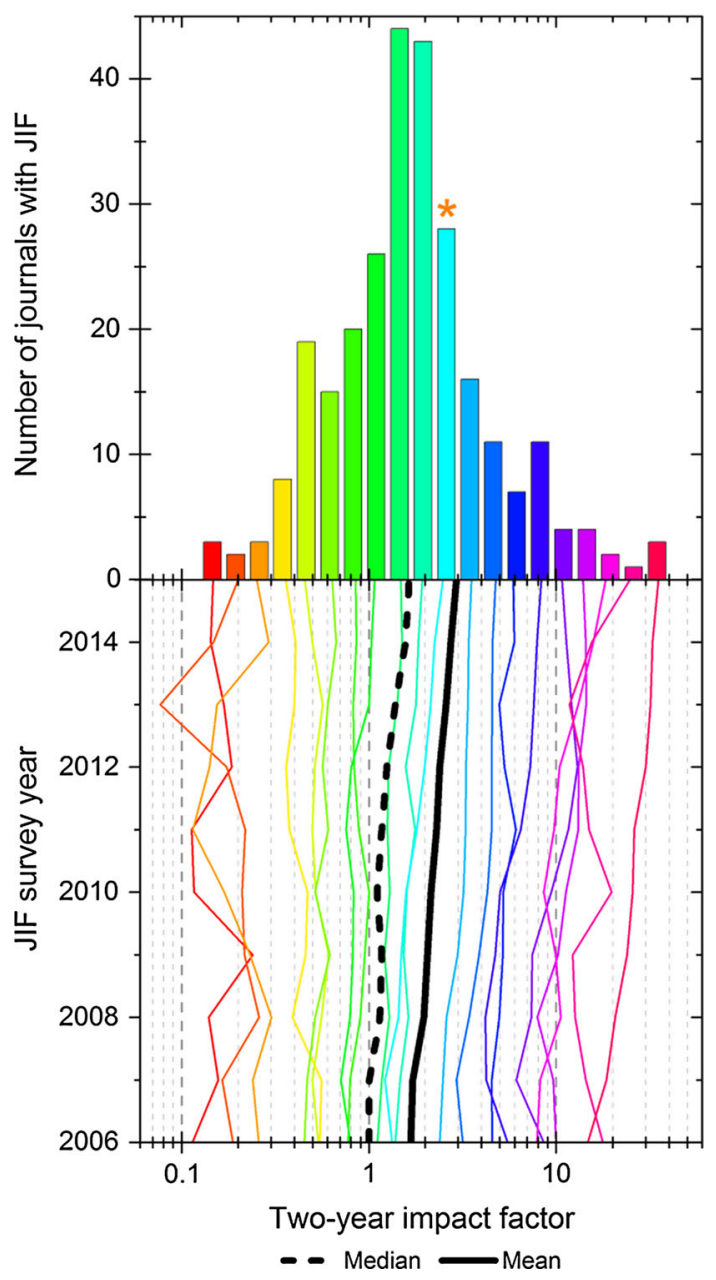

Figure 3 Top panel: histogram showing the 2015 JIF (log scale) of journals categorised as 'Materials Science, Multidisciplinary' by Thomson Reuters. The grouping that currently contains the Journal of Materials Science is marked with an orange asterisk. Bottom panel: The trend in JIF values in this category over the past decade, plotted as the mean impact factor for the journals in each bar in the top panel. The median and mean JIF values for all journals in a given survey year are plotted as dashed and solid black lines, respectively.

Second, the journals in groupings with JIFs below the median value (the 'poor') have seen their JIFs increase less than this and, in some cases, drop. This is like having a savings account with an interest rate below the inflation rate: though the balance looks bigger, its value is less than it was. For the journals with impact factors above 4 (the 'rich'), which comprise about a sixth of the titles in the 'Materials Science, Multidisciplinary' category, the story is the opposite. Five of these titles have seen their impact factors at least double in the last 10 years, and each group has increased faster than the mean in absolute terms.
Table 1 Percentage of citable items published in four materials science journals with fewer citations than the value of their 2015 Thomson Reuters journal impact factor

\begin{tabular}{lcll}
\hline Journal title & $\begin{array}{l}2015 \\
\text { JIF }\end{array}$ & $\begin{array}{l}\text { number of } \\
\text { citable items } \\
\text { (articles) }\end{array}$ & $\begin{array}{l}\text { \% citable } \\
\text { items } \\
\text { (articles) } \\
\text { below JIF }\end{array}$ \\
\hline $\begin{array}{l}\text { Journal of Materials } \\
\text { Research }\end{array}$ & 1.579 & $718(686)$ & $\begin{array}{c}65.2 \% \\
(65.6 \%)\end{array}$ \\
Journal of Materials Science & 2.302 & $1812(1768)$ & $\begin{array}{c}69.3 \% \\
(70.5 \%)\end{array}$ \\
Acta Materialia & 5.058 & $1402(1402)$ & $\begin{array}{c}69.9 \% \\
(69.4 \%)\end{array}$ \\
Advanced Materials & 18.960 & $1841(1729)$ & $\begin{array}{c}69.3 \% \\
(71.0 \%)\end{array}$ \\
\hline
\end{tabular}

Data are from Thomson Reuters' Web of Knowledge Core Collection and consists of citations from articles with a 2015 publication year to articles with a 2013 or 2014 publication year. 'Articles' refers to the Thomson Reuters document-type classification

The scale in Fig. 3 is logarithmic: each grouping represents an impact factor increase of a third. This obscures the underlying stratification of JIFs in absolute, rather than relative, terms. At the high end, the gap is vast. The $2015 \mathrm{JIF}$ for Nature Materials (red column) is 20 units higher than Advanced Materials (fuchsia column), even though they are secondnearest neighbours.

The glorification of the JIF also provides an incentive for researchers to oversell their results. Following this practice impoverishes our talent base and sets a poor example for the next generation of researchers. We are tacitly directing early career researchers to follow hot topics, rather than asking interesting questions regardless of the flavour of the month. Or, as our Editor-in-Chief has put it, the current situation is 'like kindergarten kids playing soccer: you know where the ball is because that's where all the kids are'.

Targeting journals based on impact factor, rather than remit or quality of review, increases the peer-review burden for editors and scientists as researchers. We all know that it is easy to resubmit the same article-often unmodified-to the next journal on the impact factor cascade and have another roll of the dice with the editors and referees. I suspect most academics feel they are approaching 'peer review burnout' because of this. We see the effects in the diminishing quality of reviews from time-strapped researchers. ${ }^{6}$

\footnotetext{
${ }^{6}$ Some publishers mitigate against this through internal transfers to related journals from the same company.
} 
So how do we get around this well-established problem? My next editorial will look at some of the emerging tools that give other measures of impact on an article level and an author level, including CASRAI's CRediT taxonomy initiative and Project COUNTER.

\section{References}

[1] Larivière V, Kiermer V, MacCallum CJ, McNutt M, Patterson M, Pulverer B, Swaminathan S, Taylor S, Curry S (2016) A simple proposal for the publication of journal citation distributions. bioRxiv 062109; doi: 10.1101/062109

[2] Davis, P. (2016) Can Scopus deliver a better journal impact metric? https://scholarlykitchen.sspnet.org/2016/03/07/can-sco pus-deliver-a-better-journal-impact-metric/ Accessed 3 Aug 2016

[3] McVeigh ME, Mann SJ (2009) The journal impact factor denominator: Defining citable (counted) items. JAMA 302:1107-1109. doi: 10.1001/jama.2009.1301 